\title{
FLUXOS DE NUTRIENTES ASSOCIADOS ÀS DESCARGAS DE ÁGUA SUBTERRÂNEA PARA A LAGOA MANGUEIRA (RIO GRANDE DO SUL, BRASIL)
}

Carlos F. F. Andrade*, Luis F. H. Niencheski, Karina K. Attisano e Marcio R. Milani

Instituto de Oceanografia, Universidade Federal do Rio Grande, Campus Carreiros, km 8, s/n, 96201-900 Rio Grande - RS, Brasil Isaac R. Santos

Department of Oceanography, Florida State University, Tallahassee, FL 32306, United States of America

Idel C. Milani

Departamento de Engenharia Hídrica, Centro de Desenvolvimento Tecnológico, Universidade Federal de Pelotas, Campus Porto, Rua Gomes Carneiro, 1, 96019-610 Pelotas - RS, Brasil

Recebido em 1/9/10; aceito em 19/5/11; publicado na web em 29/6/11

\begin{abstract}
NUTRIENTS FLUXES FROM GROUNDWATER DISCHARGE INTO MANGUEIRA LAGOON (RIO GRANDE DO SUL, BRASIL). This study assesses the importance of groundwater discharge to dissolved nutrient levels in Mangueira Lagoon. A transect of an irrigation canal in the margin of Lagoon demonstrated a strong geochemical gradient due to high groundwater inputs in this area. Using ${ }^{222} \mathrm{Rn}$ as a quantitative groundwater tracer, we observed that the flux of dissolved inorganic nitrogen (DIN), silicate and phosphate (1178 and 1977; 26190 and 35652; 167 and $188 \mathrm{~mol} \mathrm{~d}^{-1}$ for winter and summer, respectively) can continually supply/ sustain primary production. The irrigation canals act as an artificial underground tributary and represent a new source of nutrients to coastal lagoons.
\end{abstract}

Keywords: nutrients; coastal lagoons; submarine groundwater discharge.

\section{INTRODUÇÃO}

As descargas de água subterrânea, apesar de serem consideradas por hidrólogos como uma das parcelas atuantes no abastecimento de água nos sistemas lacustres e costeiros, ${ }^{1,2}$ apenas recentemente foram reconhecidas como uma das importantes fontes de elementos dissolvidos para as águas superficiais. ${ }^{3-5}$

Em geral, as concentrações dos nutrientes presentes nas águas subterrâneas são mais elevadas do que as encontradas em rios, lagos e estuários, compensando assim o menor fluxo das águas subterrâneas com relação ao escoamento superficial. ${ }^{3,6,7}$ Uma vez que estes fluxos ocorrem ao longo de áreas muito extensas, o aporte total de nutrientes para um sistema lacustre ou costeiro pode ser significativo. ${ }^{8}$

A Planície Costeira do Rio Grande do Sul é privilegiada pelo grande número de rios e lagoas, destacando-se em volume de água, a Laguna dos Patos e as Lagoas Mirim e Mangueira. Como consequência do volume de água disponível, os ambientes costeiros como a Lagoa Mangueira, com uma baixa densidade demográfica em sua área de entorno, têm seus usos preferenciais ligados diretamente à agricultura, pecuária, pesca e à recreação. A restinga localizada entre essas lagoas e o mar é dominada por sedimentos permeáveis, formando uma zona de transição entre a água superficial e água subterrânea. ${ }^{9}$

O maior consumo de água da Lagoa Mangueira ocorre no período de verão, devido ao cultivo de arroz na área de entorno, onde a retirada de água aliada às perdas por evaporação diminuem drasticamente os níveis de água da Lagoa. ${ }^{10,11} \mathrm{O}$ fornecimento da água para a irrigação requer a construção de canais na região marginal e de levantes que permitem o bombeamento e escoamento das águas até as lavouras. Estes canais são abertos na margem oeste da Lagoa e seu aprofundamento para uma melhor captação de água, inclusive nos períodos de estiagem, que coincide com o período de plantio realizado no verão, modifica a interface margem/lagoa. Santos et al., ${ }^{12}$ usando ${ }^{222} \mathrm{Rn}$ como traçador geoquímico, demonstraram importante

*e-mail: pgofcfa@furg.br advecção de água subterrânea, principalmente na região dos canais. $\mathrm{O}{ }^{222} \mathrm{Rn}$ é uma das formas de abordagem mais atuais para a quantificação de advecção de água em ambientes aquáticos, principalmente os de água doce, ${ }^{13}$ pois além de ser conservativo e de fácil detecção, ${ }^{14}$ sua concentração é mais elevada nas águas subterrâneas em relação às águas superficiais, ${ }^{15}$ estando sua ocorrência nos corpos hídricos associada aos fluxos advectivos.

Os processos que atuam no aporte e manutenção das concentrações dos nutrientes em um corpo hídrico atuam de forma concomitante. É importante o conhecimento e a avaliação dos processos que controlam a produção primária, principalmente quando se trata de ambientes que apresentam estado trófico variado, como o caso de muitas lagoas costeiras. ${ }^{16} \mathrm{O}$ presente estudo teve como objetivo investigar os fluxos subterrâneos de nutrientes em áreas influenciadas por canais de irrigação e a influência destes fluxos na qualidade e manutenção da produtividade das águas superficiais da Lagoa Mangueira.

Estudos semelhantes sobre os fluxos advectivos subterrâneos são raros e focados em aportes para áreas oceânicas. ${ }^{17}$ Niencheski et $a l .{ }^{18}$ usaram isótopos de rádio para quantificar aportes subterrâneos ao longo da plataforma continental do RS. Em Ubatuba (SP), isótopos de rádio e radônio foram usados para quantificar os aportes de água subterrânea em uma enseada marinha. ${ }^{19-21}$ Entretanto, o grau de conhecimento do estado qualitativo e a avaliação adequada das características dos aquíferos costeiros ainda é uma incógnita para muitas regiões da América do Sul. ${ }^{22}$ Este trabalho é o primeiro a avaliar a relação do aquífero com as lagoas na região costeira na América do Sul, a partir dos fluxos de nutrientes associados aos aportes subterrâneos.

\section{PARTE EXPERIMENTAL}

\section{Área de estudo}

A Lagoa Mangueira (Figura 1S, material suplementar) está confi- 
nada entre barreiras geológicas datadas entre o período Pleistocênico e Holocênico. ${ }^{23}$ É um sistema raso, fechado, sem efeito de maré e faz parte do maior complexo lagunar do mundo - o sistema Patos-MirimMangueira. A Lagoa Mangueira possui uma extensão de $96 \mathrm{~km}$ de comprimento por 7,6 km de largura no seu ponto mais largo e uma profundidade média de $2,5 \mathrm{~m}$, não apresentando tributários e nem comunicação superficial com o Oceano Atlântico. ${ }^{24}$ Este extenso espelho d'água apresenta um volume aproximado de $700.000 .000 \mathrm{~m}^{3}{ }^{25}$

A Lagoa Mangueira possui como limite norte o Banhado do Taim, que é conectado com as águas da Lagoa Mirim, através de um canal artificial. As perdas de água da Lagoa Mangueira ocorrem por evaporação, fluxos subsuperficiais para o oceano, bombeamento para irrigação de arroz e fluxos superficiais sazonais em direção ao banhado do Taim ou deste, para a Lagoa Mirim. ${ }^{25}$

O clima dessa região é do tipo subtropical, com predomínio de uma precipitação média anual de $1100 \mathrm{~mm}$ e uma temperatura média anual de $18^{\circ} \mathrm{C}$. O período de inverno é caracterizado como sendo frio e chuvoso, e o período de verão como quente e seco, além de ventos bastante intensos, obedecendo ao padrão da região sul que mantém as águas da Lagoa Mangueira bem misturadas. ${ }^{26}$

\section{Coleta de amostras}

As coletas de água superficiais e subterrâneas foram realizadas em agosto de 2006 (inverno) e janeiro de 2007 (verão). As amostras das águas superficiais da Lagoa Mangueira foram coletadas com uma garrafa de van Dorn, em 29 estações no inverno e 13 estações no verão (Figura 1S, material suplementar). Foi realizado em agosto de 2006 um perfil horizontal em um dos canais utilizados para a captação de água para a lavoura. Ao longo deste perfil, coletas de água superficial foram feitas em 7 pontos, no sentido canal-lagoa, nas distâncias de 0 , $50,100,200,400,700$ e $1000 \mathrm{~m}$, sendo o ponto 0 localizado próximo à casa de bombas (Figura $1 \mathrm{~S}$, material suplementar).

As coletas de água subterrânea foram realizadas em 8 poços piezométricos multiníveis localizados na margem oeste da Lagoa Mangueira, atingindo profundidades de 1 a $5 \mathrm{~m}$, com coletas a cada metro. O sistema de coleta consistiu de varas de aço inox com $1 \mathrm{~m}$ de comprimento, acopláveis de acordo com a profundidade pretendida, e uma ponteira inerte. ${ }^{6}$ Uma mangueira Masterflex ${ }^{\circledR}$, no interior dessas varas, conectou a ponteira à bomba peristáltica.

As coletas foram seguidas de filtração (filtro de acetato de celulose $-0,45 \mu \mathrm{m}$ ), sendo que para as águas subterrâneas foi utilizado sistema fechado com auxílio de filter holder Millipore ${ }^{\circledR}$. As amostras coletadas foram encaminhadas ao laboratório em caixas de isopor com unidades de gelo. Ao chegarem ao laboratório, as amostras de nutrientes foram armazenadas por congelamento a $-12{ }^{\circ} \mathrm{C}$ até o momento da análise. Para a obtenção da clorofila $a$ filtrou-se $60 \mathrm{~mL}$ de água superficial da Lagoa (zona fótica) em filtro de fibra de vidro GFC, sendo este imediatamente congelado a $-16^{\circ} \mathrm{C}$.

\section{Parâmetros avaliados}

Foram determinados in situ $\mathrm{pH}$, salinidade e condutividade utilizando, respectivamente, pHmetro (Metler Toledo MP120) e termossalinômetro (YSI 30, Yellow Springs). Os nutrientes dissolvidos $\left(\mathrm{PO}_{4}^{3-}, \mathrm{SiO}_{4}^{4-}, \mathrm{NH}_{4}^{+}, \mathrm{NO}_{2}^{-}\right.$e $\left.\mathrm{NO}_{3}^{-}\right)$e material em suspensão (MS) foram determinados seguindo a metodologia descrita em Baumgarten et al $^{27}$ e Strickland e Parsons. ${ }^{28}$ Os nitrogenados inorgânicos totais (NIT) foram obtidos através da soma das concentrações de amônio, nitrato e nitrito dissolvidos. Clorofila $a$ foi determinada por método fluorimétrico após extração do pigmento com acetona a 90\%. ${ }^{29}$ Análises de radônio $\left({ }^{222} \mathrm{Rn}\right.$ ) foram realizadas in situ com o equipamento RAD-7 (Durridge Co, Inc.). Descrição da metodologia e dos resultados de aportes de água subterrânea, com o uso de ${ }^{222} \mathrm{Rn}$, estão apresentados em Santos et al.. ${ }^{12}$

Para obtenção de dados de pressão hidrostática interna foi instalado um sensor $\mathrm{HOBO}^{\circledR}$ (com registro a cada $30 \mathrm{~min}$ ) em um poço permanente com $9 \mathrm{~m}$ de profundidade, situado a $250 \mathrm{~m}$ da margem oeste da Lagoa. Essa profundidade corresponde às águas do lençol freático superficial que, provavelmente, interagem com as águas superficiais da Lagoa. Os dados de nível da Lagoa Mangueira foram obtidos através de medições diárias em régua com sensor instalada próxima ao poço. Para avaliar a interação da pressão do aquífero com o nível das águas superficiais da Lagoa Mangueira foi aplicada a análise estatística de correlação de Pearson utilizando o programa PAST. ${ }^{30}$

\section{RESULTADOS E DISCUSSÃO}

\section{Distribuição dos nutrientes na Lagoa Mangueira}

O período de inverno/2006 foi marcado pela alta concentração de fosfato e silicato associados à região marginal oeste (Figura 1). Santos et. al. ${ }^{31}$ demonstraram que neste período o deságue superficial na região marginal associado à intensa precipitação pluviométrica (300 mm) diminuiu as concentrações de elementos maiores dissolvidos, exceto fluoreto, que teve suas concentrações aumentadas. Este último é indicador de aporte de água da chuva. Esta precipitação acumulada elevou a quantidade de material em suspensão (Figura 1) ocasionando a remobilização de fosfato contido no sedimento. Assim, o deságue continental e a lixiviação do solo utilizado no plantio de arroz promoveram o aumento das concentrações de fosfato, sendo que o silicato acompanhou esta tendência na parte central da Lagoa onde um pequeno acréscimo das concentrações de NIT também foi observado.

Os elevados valores de NIT para o período de verão/2007 na região central da Lagoa foram impulsionados pela alta concentração de nitrato (Tabela 1), sendo dos nutrientes nitrogenados a espécie mais persistente em ambientes oxidados, podendo percorrer maiores distâncias a partir de sua fonte. Como a metade sul da Lagoa concentra $70 \%$ dos canais de irrigação, ${ }^{12}$ o que demonstra o uso extensivo do solo para a agricultura de arroz irrigado, o incremento de nitrato na Lagoa está relacionado ao manejo ineficiente e consequente perda de água da lavoura fertilizada no período de cultivo. ${ }^{32}$

A região norte da Lagoa, inserida dentro de uma zona de proteção ambiental (Estação Ecológica do Taim), caracteriza-se por não apresenta qualquer atividade humana em sua área de entorno, no entanto, este local demonstrou concentrações elevadas de fosfato e NIT, tanto para o inverno/2006 quanto para o verão/2007. Dentre as principais diferenças deste local estão as características do substrato sedimentar, rico em matéria orgânica e com uma cobertura vegetal composta por macrófitas, uma altura de coluna d'água menor (máxima de $3 \mathrm{~m}$ ) e constante interação com as águas do banhado do Taim. ${ }^{11,33} \mathrm{~A}$ ação dos ventos, principal agente na circulação das águas da Lagoa, intensifica os intercâmbios químicos entre os compartimentos sedimentar e coluna d'água, ${ }^{34}$ através da ressuspensão dos sedimentos depositados, e ativa os processos de reciclagens e regeneração bêntica de compostos nitrogenados e fosfatados constituintes da matéria orgânica. ${ }^{35} \mathrm{Na}$ região norte da Lagoa o intenso processo de ciclagem de nutrientes, por mineralização da matéria orgânica, atua como fonte natural e permanente de nutrientes para a coluna d'água ao longo do ano.

\section{Transecto em um canal de irrigação}

Os canais de irrigação são uma importante fonte de água subterrânea para a Lagoa Mangueira, contribuindo com aproximadamente 


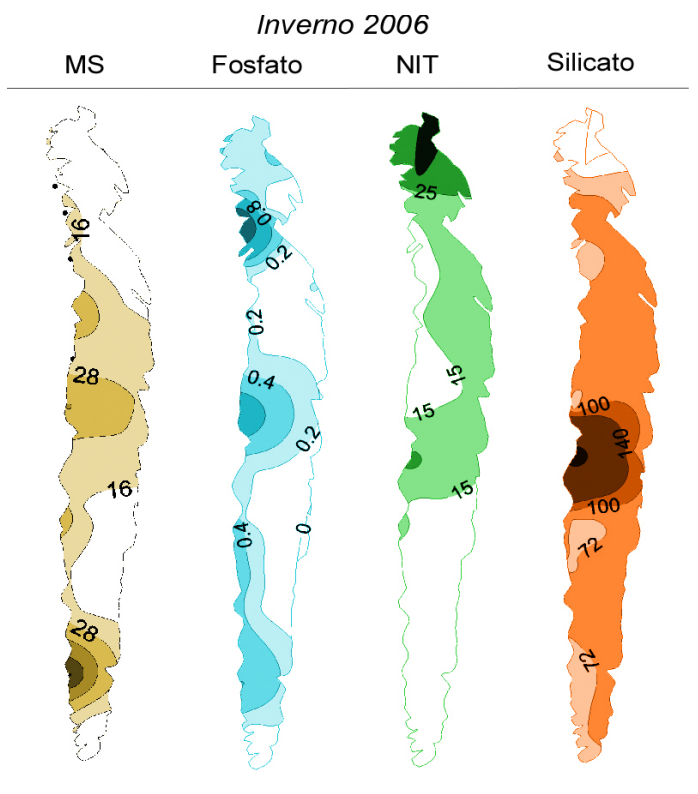

Verão 2007

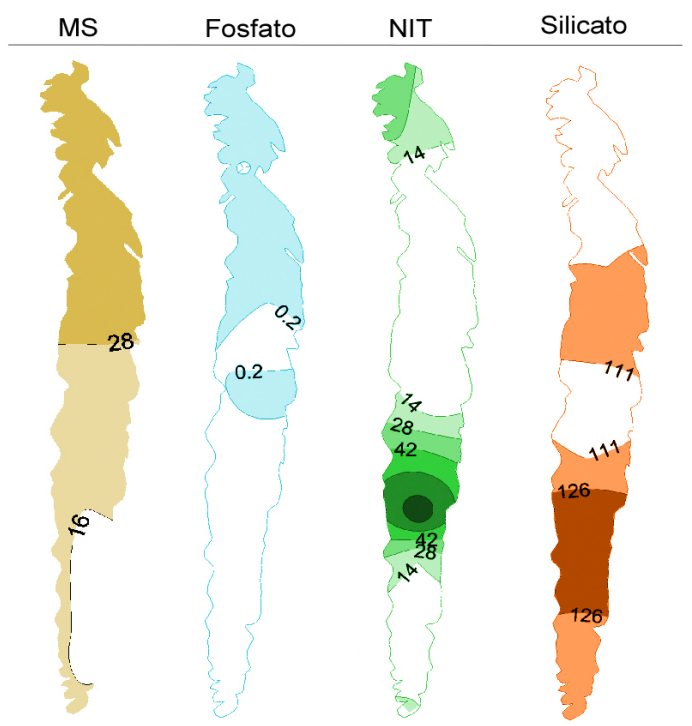

Figura 1. Distribuição das concentrações dos nutrientes ( $\mu$ mol $\left.L^{-1}\right)$ e material em suspensão (MS - mg $\left.L^{-1}\right)$ na água superficial da Lagoa Mangueira. Cores escuras representam valores elevados

$70 \%$ do volume total de água subterrânea que abastece o corpo lagunar. ${ }^{12}$ Esses canais existem devido à necessidade de captação de água para as lavouras através do bombeamento da água da Lagoa. A captação de água se inicia logo após o plantio do arroz e dura aproximadamente de 3 a 4 meses. ${ }^{36}$ Os canais requerem constante manutenção através do seu aprofundamento, que retira várias camadas de sedimento superficiais com baixa condutividade hidráulica, expondo os sedimentos mais permeáveis das camadas sedimentares mais profundas. Tal diferença foi investigada através da qualidade hidroquímica de um destes canais a partir de amostras coletadas ao longo de um transecto no sentido canal-Lagoa. Os teores de nutrientes dissolvidos encontrados seguiram a tendência do ${ }^{222} \mathrm{Rn}$, um traçador confiável de água subterrânea. ${ }^{37}$ As maiores concentrações foram encontradas próximo ao local de bombeamento da água para as lavouras, diminuindo em direção à Lagoa (Figura 2), o que indicou que os aportes de água subterrânea estão contribuindo para o incremento de nutrientes na região dos canais.

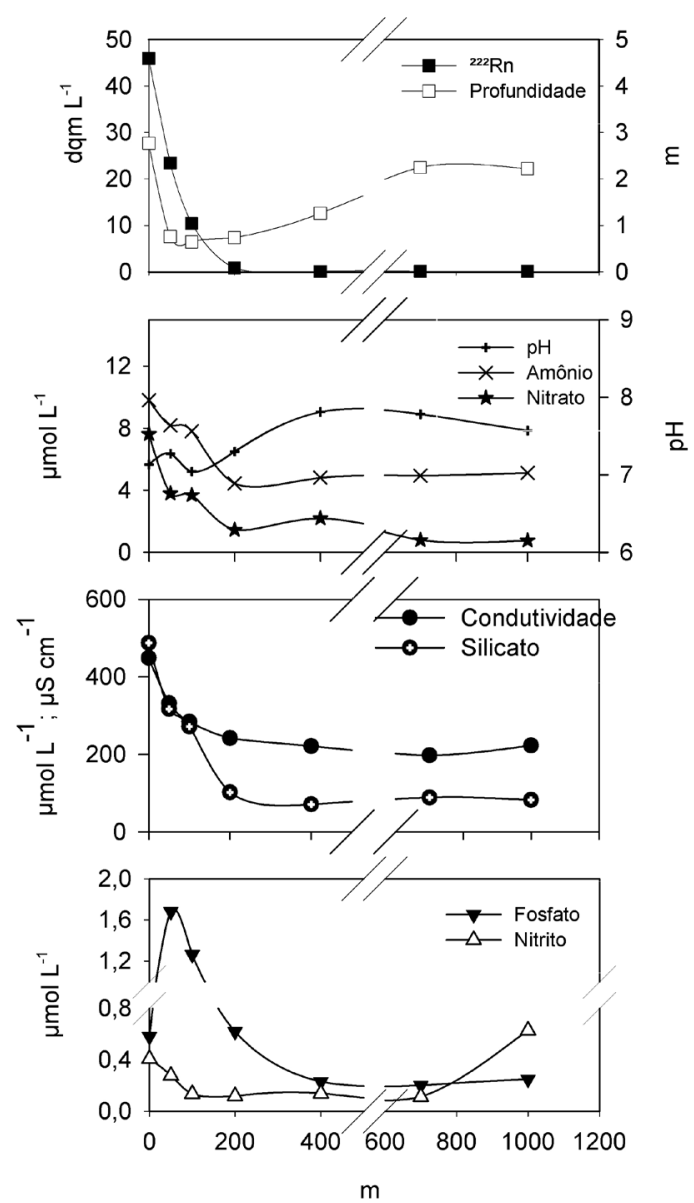

Figura 2. Distribuição longitudinal de nutrientes ( $\left.\mu \mathrm{mol} \mathrm{L}^{-1}\right)$, condutividade $\left(\mu \mathrm{S} \mathrm{cm}{ }^{-1}\right) e^{222} \mathrm{Rn}$ (dpm $\left.\mathrm{L}^{-1}\right)$ da água amostrada ao longo do perfil ortogonal e profundidade $(m)$ do canal de captação de água. O ponto zero corresponde à casa de bombas

Os teores de nutrientes nos canais são resultado da mistura entre a água superficial e do aporte de água subterrânea. Como consequência, a busca por um dos membros finais dos processos de mistura deve ser obtida junto à fonte representativa do aporte de água subterrânea. Para tanto, poços piezométricos foram instalados ao longo da margem oeste, para a coleta de água subterrânea em diferentes profundidades e locais.

\section{Monitoramento do nível da Lagoa e água subterrânea}

Como comprovar que as águas subterrâneas possuem conexão com as águas superficiais da Lagoa Mangueira? A análise de resultados de pressão interna de um poço permanente, com $9 \mathrm{~m}$ de profundidade e a aproximadamente $4 \mathrm{~m}$ acima do nível médio de água da Lagoa Mangueira, comparados com dados de nível superficial, durante um período de 7 meses (Figura 3) demonstra uma clara interação entre a pressão do aquífero e o nível da Lagoa $(r=0,82$, $\mathrm{p}<0,01$ ). Como a Lagoa possui uma profundidade média de $2,5 \mathrm{~m}, \mathrm{o}$ lençol freático conecta-se e interage com sua coluna d'água, ao longo de toda a região marginal da Lagoa, devido à atuação do gradiente topográfico e a dominância de sedimentos arenosos permeáveis. Ainda, a ação das forçantes hidrológicas e meteorológicas e o uso predominante das águas da Lagoa para a agricultura (com pico máximo de consumo no verão) resultam na variação do nível de água na Lagoa Mangueira e supõe-se que estas também incidam sobre a qualidade da água subterrânea. 


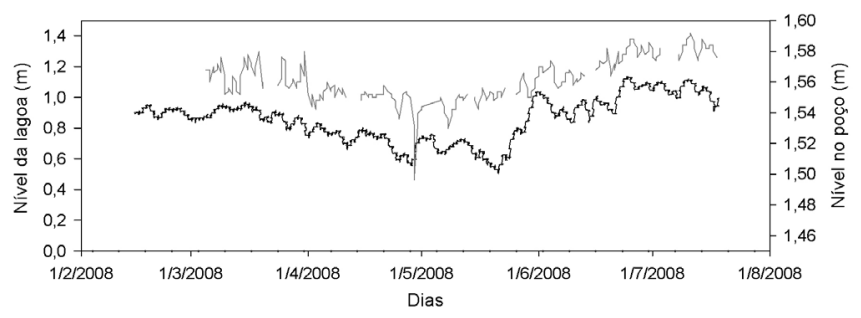

Figura 3. Nível diário em metros da Lagoa Mangueira (preto) e variação de pressão diária, em metro de coluna d'água, no poço 1 (cinza)

\section{Fluxos subterrâneos de nutrientes}

A Tabela 1 apresenta a concentração de nutrientes associados às águas subterrâneas e superficiais para os períodos de inverno e verão. Para efeitos comparativos, a Tabela 1 apresenta também concentrações na região interna do canal de irrigação (entre 0 e $50 \mathrm{~m}$ ). Tanto para o verão como para o inverno, as águas subterrâneas apresentam um elevado fator de enriquecimento em nutrientes, principalmente fosfato (Figura 4) enriquecendo as águas do canal quando estas se misturam. A dinâmica da água nos sedimentos permeáveis nas regiões de interface entre água subterrânea e água superficial é um dos processos que pode proporcionar o incremento de nutrientes nas regiões marginais dos corpos hídricos. ${ }^{4,38}$ Assim, conforme as características do substrato sedimentar, estas interações podem ser mais ou menos significativas na liberação dos nutrientes.

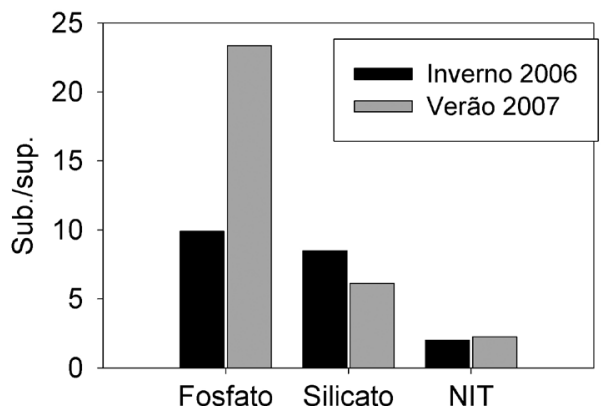

Figura 4. Razão das concentrações médias de nutrientes ( $\mu$ mol $L^{-1}$ ) encontrados nas águas subterrâneas e superficiais para os períodos de inverno de 2006 e verão de 2007

Essa fonte de nutrientes, até o presente momento, nunca havia sido considerada de forma quantitativa para uma lagoa costeira no Brasil. Para quantificar o aporte de nutrientes via água subterrânea foram usadas as taxas médias de advecção no inverno $\left(18 \mathrm{~cm} \mathrm{~d}^{-1}\right)$ e verão $\left(21 \mathrm{~cm} \mathrm{~d}^{-1}\right)$, que resultam em fluxos de água subterrânea de 36.740 e $42.660 \mathrm{~m}^{3} \mathrm{~d}^{-1}$, respectivamente. Esses dados referem-se à área ocupada por 36 canais de irrigação $\left(0,2 \mathrm{~km}^{2}\right)$ e foram estimados com o uso de ${ }^{222} \mathrm{Rn}$ como traçador geoquímico natural. ${ }^{12}$ Utilizando a concentração média dos nutrientes no lençol freático multiplicada pelo aporte de água subterrânea da região dos canais obtêm-se os fluxos de nutrientes para os respectivos períodos (Tabela 1).

O fluxo dos canais em direção a Lagoa é interrompido, em parte, a cada ano no período de plantio, quando o escoamento da água é forçado por bombeamento a fluir em direção à lavoura. Entretanto, em função do sistema adotado de rodízio de terras cultiváveis, aproximadamente metade dos 36 canais são utilizados em cada ano, para não exaurir o solo. Ainda, o tempo de funcionamento das bombas é de $12 \mathrm{~h} /$ dia. $^{12}$ Dessa forma, a retirada da água dos canais para a lavoura causa um decréscimo de apenas $6 \%$ no aporte total de água subterrânea para a Lagoa Mangueira.

\section{Influência da água subterrânea na produtividade primária}

Como o fluxo de nutrientes para as regiões costeiras condiciona o potencial de enriquecimento dessas águas e as taxas de produção primária ${ }^{4}$ torna-se importante avaliar de que maneira os nutrientes advectados contribuem para o sustento da produção primária na Lagoa Mangueira. Entretanto, poucos estudos foram desenvolvidos nesta Lagoa e a taxa de produção primária ainda não foi calculada. Para suprir essa lacuna, os dados de clorofila $a$ obtidos durante o verão de 2007 (Tabela 1) foram usados para estimar a produção primária.

Com base na metodologia descrita em Odum,${ }^{39}$ com modificações, a diferença entre valores mínimos de $\mathrm{Cl} a$ (dados obtidos na $1^{\mathrm{a}} \mathrm{h}$ do dia - 0,99 $\left.\mathrm{mg} \mathrm{L}^{-1}\right)$ e os valores máximos $\left(13,74 \mathrm{mg} \mathrm{L}^{-1}\right)$, forneceram a produção fitoplanctônica da Lagoa $\left(12,75 \mathrm{mg} \mathrm{L}^{-1}\right)$. Este valor foi dividido pelo período amostral entre estas determinações $(12 \mathrm{~h})$ e multiplicado pelo tempo diário de irradiação solar (14 h para o verão), resultando uma taxa de $14,8 \mathrm{mg} \mathrm{Cl} a \mathrm{~m}^{-3} \mathrm{dia}^{-1}$. Para converter os valores de clorofila $a$ para carbono, foi aplicada a razão $\mathrm{Cl} a$ :C igual a $40,{ }^{40}$ sendo que a razão Cla:C para organismos acima de 0,9 $\mu \mathrm{m}$ pode variar de 25 a $50 .{ }^{41}$ Multiplicando o valor obtido de carbono pela profundidade de penetração da luz na coluna d'água (zona fótica) de $0,5 \mathrm{~m},{ }^{42}$ obtém-se uma taxa de produção primária de 296 $\mathrm{mg} \mathrm{C} \mathrm{m}{ }^{-2} \mathrm{dia}^{-1}$. Este valor se encontra dentro das variações sazonais encontradas para a Lagoa dos Patos, reservatórios e Lagoas Costeiras de clima subtropical. ${ }^{43-46}$ Existe ainda incertezas nesta estimativa, pois não engloba a produção primária durante todo o ciclo sazonal ao longo da Lagoa, onde as frações norte e sul apresentam variação na distribuição das espécies fitoplanctônicas.

Através do uso da relação de Redfield ${ }^{47}$ foi estimada a massa de $\mathrm{N}$, P e Si necessária para sustentar a produção primária da coluna d'água

Tabela 1. Concentração média e desvio padrão dos nutrientes ( $\left.\mu \mathrm{mol} \mathrm{L}^{-1}\right)$ e clorofila $a\left(\mu \mathrm{g} \mathrm{L}^{-1}\right)$ na água subterrânea marginal oeste, superficial e no canal $(0-50$ m) e fluxos de nutrientes, períodos de inverno e verão

\begin{tabular}{|c|c|c|c|c|c|c|c|}
\hline & \multicolumn{4}{|c|}{ Inverno 2006} & \multicolumn{3}{|c|}{ Verão 2007} \\
\hline & Canal 0-50 m & Subterrânea $(\mathrm{n}=10)$ & Superficial $(n=27)$ & Fluxos mol d ${ }^{-1}$ & Subterrânea $(n=15)$ & Superficial $(n=13)$ & Fluxos mol d ${ }^{-1}$ \\
\hline $\mathrm{PO}_{4}^{3-}$ & 1,68 & $4,55 \pm 4,11$ & $0,87 \pm 2,40$ & 167,23 & $4,42 \pm 2,58$ & $0,19 \pm 0,06$ & 188,58 \\
\hline $\mathrm{SiO}_{4}^{4-}$ & 487,64 & $712,87 \pm 361,37$ & $83,81 \pm 79,79$ & 26190,94 & $835,73 \pm 374,77$ & $116,35 \pm 13,37$ & 35652,43 \\
\hline $\mathrm{NH}_{4}^{+}$ & 9,81 & $28,63 \pm 58,67$ & $8,27 \pm 2,53$ & 1051,79 & $41,14 \pm 69,16$ & $3,60 \pm 4,36$ & 1755,22 \\
\hline $\mathrm{NO}_{2}^{-}$ & 0,40 & $0,26 \pm 0,17$ & $0,16 \pm 0,09$ & 9,65 & $1,67 \pm 4,62$ & $0,14 \pm 0,02$ & 71,04 \\
\hline $\mathrm{NO}_{3}^{-}$ & 7,62 & $3,19 \pm 3,28$ & $7,73 \pm 6,42$ & 117,27 & $3,56 \pm 7,13$ & $14,23 \pm 22,26$ & 151,67 \\
\hline NIT & 17,83 & $32,08 \pm 59,43$ & $16,16 \pm 7,24$ & 1178,71 & $46,36 \pm 73,21$ & $17,97 \pm 22,62$ & 1977,92 \\
\hline NIT/P & 7,27 & 7,05 & 18,57 & - & 10,48 & 94,58 & - \\
\hline $\mathrm{Cl} a$ & - & - & - & - & - & $7,26 \pm 4,84$ & - \\
\hline
\end{tabular}


da Lagoa. A partir desse valor, foi avaliada a efetiva contribuição dos canais para a área total da Lagoa $\left(800 \mathrm{~km}^{2}\right)$, como fonte de nutrientes. A contribuição estimada a partir da média dos fluxos de nutrientes corresponde a $0,01,0,006$ e $2,3 \%$ para fosfato, nitrogênio total inorgânico e silicato, respectivamente. Embora esses valores sejam aparentemente baixos, os fluxos subterrâneos são responsáveis pelo aporte alóctone de nutrientes (produção nova) e que permanecem no sistema fechado do corpo lagunar. Uma vez na Lagoa, os nutrientes oriundos da água subterrânea podem ser regenerados constantemente, sustentando altas taxas de produção primária por um longo tempo.

\section{Comparação com a região oceânica ao largo da Lagoa dos Patos}

Os fluxos dos canais podem suportar a produção primária da Lagoa Mangueira ao longo do tempo através do aporte contínuo de nutrientes, diferentemente do observado para a região oceânica ao largo da Lagoa dos Patos, onde estudos demonstraram que os fluxos de nutrientes nesta região suportam diretamente $50 \%$ da produção primária da zona de praia. ${ }^{18}$ Enquanto os aportes subterrâneos para a Lagoa Mangueira ficam nela retidos, os aportes para a plataforma continental são transferidos para o oceano aberto em escalas temporais de dias-semanas.

Os aportes de água subterrânea nas regiões oceânicas ao largo da Lagoa dos Patos e pelos canais da Lagoa Mangueira ocorrem através de áreas distintas (2.200 e 0,2 km² , respectivamente) onde o volume de água que aporta em cada sistema apresenta grandes diferenças (Tabela 2).

Tabela 2. Teores de nutrientes normalizados aplicando a descarga média de água subterrânea que aporta nos canais e a descarga da restinga

\begin{tabular}{|c|c|c|}
\hline & Canais & Restinga \\
\hline Água subterrânea $\left(\mathrm{m}^{3} \mathrm{dia}^{-1}\right)$ & 39700 & $3,1 \times 10^{7}$ \\
\hline $\mathrm{PO}_{4}^{3-}\left(\mathrm{mol} \mathrm{m}^{-3}\right)$ & $4,48 \times 10^{-3}$ & $8,06 \times 10^{-3}$ \\
\hline $\mathrm{SiO}_{4}{ }^{4-}\left(\mathrm{mol} \mathrm{m}^{-3}\right)$ & 0,78 & 0,75 \\
\hline $\mathrm{NH}_{4}^{+}\left(\mathrm{mol} \mathrm{m}^{-3}\right)$ & $3,53 \times 10^{-2}$ & $3,71 \times 10^{-2}$ \\
\hline $\mathrm{NO}_{2}^{-}\left(\mathrm{mol} \mathrm{m}^{-3}\right)$ & $1,01 \times 10^{-3}$ & $6,45 \times 10^{-5}$ \\
\hline $\mathrm{NO}_{3}^{-}\left(\mathrm{mol} \mathrm{m}^{-3}\right)$ & $3,38 \times 10^{-3}$ & $2,77 \times 10^{-3}$ \\
\hline $\operatorname{NIT}\left(\mathrm{mol} \mathrm{m}^{-3}\right)$ & 0,04 & 0,04 \\
\hline
\end{tabular}

Para comparar esses ambientes quanto ao incremento de nutrientes é necessário normalizá-los. Nesse caso, o fluxo de nutrientes para cada ambiente foi dividido pela descarga de água doce subterrânea. Os resultados obtidos demonstram uma grande similaridade para os nutrientes nos dois ambientes considerados (Tabela 2). Isto é coerente, pois ambas regiões são sistemas deposicionais da Planície Costeira do Rio Grande do Sul, sistemas "Laguna-Barreira" Pleistocênicos/ Holocênicos. ${ }^{23}$ Como consequência, os mecanismos que regem a dissolução, mineralização e lixiviação dos constituintes dissolvidos nos sedimentos permeáveis e contribuem para a qualidade hidroquímica do aquífero ao longo da costa, possuem o mesmo potencial de enriquecimento das águas superficiais.

\section{CONCLUSÕES}

A Lagoa Mangueira é reconhecida pela ausência de tributários superficiais. Neste estudo foi demonstrado que os canais artificiais utilizados na captação de água da Lagoa para as lavouras de arroz atuam como tributários para a Lagoa, contribuindo com água subterrânea mais rica em nutrientes.
A advecção de água rica em nutrientes ocorre na região dos canais, ocasionando inicialmente a modificação da água em seu interior, e na região adjacente próxima. Porém, essa fonte nova de nutrientes não é capaz de suportar a produção primária de forma direta em todo o corpo lagunar. É provável que os nutrientes oriundos da água subterrânea sejam reciclados várias vezes na lagoa, sustentando a produção primária de forma contínua. Esse sistema provavelmente possui processos de remineralização bêntica bastante eficazes na interface, que necessitam ser investigados.

\section{MATERIAL SUPLEMENTAR}

A Figura 1S é composta por um mapa georreferenciado da fração extremo sul do estado do Rio Grande do Sul e apresenta a localização geográfica dos pontos amostrais para a região de estudo. Está disponível em http://quimicanova.sbq.org.br, na forma de arquivo PDF, com acesso livre.

\section{AGRADECIMENTOS}

C. Andrade possui uma bolsa CNPq/CTHidro-40 (141554/07-0). Este projeto foi financiado pelo CNPq (552715/2005-0, 301219/2003-6 e 305375/2006-7) e FAPERGS (0.518.017) concedidos a L. Niencheski. Os autores também agradecem a T. Pereira e V. Miranda pela assistência no campo e à L. Bohmer pelo auxílio na análise de nutrientes. Somos muito gratos à Estação Ecológica do Taim (ICM-Bio), Sr. A. Giudice e Sr. I. M. Rodrigues, que providenciaram abrigo durante as expedições.

\section{REFERÊNCIAS}

1. Tucci, C. E. M.; Hidrologia - Ciência e Aplicação, $4^{\mathrm{a}}$ ed., ABRH: Porto Alegre, 2007.

2. Fetter, C. W.; Applies Hydrogeology, $4^{\text {th }}$ ed., Prentice-Hall, Inc.: New Jersey, 2001.

3. Moore, W. S.; Nature 1996, 380, 2.

4. Slomp, C. P.; van Cappellen, P.; J. Hydrol. 2004, 295, 64.

5. Burnett, W. C.; Aggarwal, P. K.; Aureli, A.; Bokuniewicz, H.; Cable, J. E.; Charette, M. A.; Kontar, E.; Krupa, S.; Kulkarni, K. M.; Loveless, A.; Moore, W. S.; Oberdorfer, J. A.; Oliveira, J.; Ozyurt, N.; Povinec, P.; Privitera, A. M. G.; Rajar, R.; Ramessur, R. T.; Scholten, J.; Stieglitz, T.; Taniguchi, M.; Turner, J. V.; Sci. Total Environ. 2006, 367, 498.

6. Charette, M. A.; Sholkovitz, E. R.; Geochim. Cosmochim. Acta 2006, 70,15 .

7. Windom, H. L.; Moore, W. S.; Niencheski, L. F. H.; Jahnke, R. A.; Mar. Chem. 2006, 102, 252.

8. Santos, I. R.; Burnett, W. C.; Dittmar, T.; Suryaputra, I. G. N. A.; Chanton, J.; Geochim. Cosmochim. Acta 2009, 73, 1325.

9. Ullman, W. J.; Chang, B.; Miller, D. C.; Madsen, J. A.; Estuar. Coast. Shelf Sci. 2003, 57, 539 .

10. Andrade, C. F. F. d.; Milani, I. C. B.; Attisano, K. K.; Niencheski, L. F. H.; Santos, I. R. d.; Burnett, W.; Milani, M. R.; Contreira, L.; III Seminário e Workshop em Engenharia Oceânica, Rio Grande, Brasil, 2008.

11. Ferreira, T. F.; Tese de Doutorado, Universidade Federal do Rio Grande do Sul, Brasil, 2009.

12. Santos, I. R.; Niencheski, F.; Burnett, W.; Peterson, R.; Chanton, J.; Andrade, C. F. F.; Milani, I. B.; Schmidt, A.; Knoeller, K.; J. Hydrol. 2008, 353, 275.

13. Burnett, W. C.; Dulaiova, H.; Cont. Shelf Res. 2006, 26, 862.

14. Cable, J. E.; Burnett, W. C.; Chanton, J. P.; Weatherly, G. L.; Earth Planet. Sc. Lett. 1996, 144, 591.

15. Corbett, D. R.; Burnett, W. C.; Cable, P. H.; Clark, S. B.; J. Hydrol. 1997, 203, 209. 
16. Ferreira, T. F.; Jr., C. R. F.; Collischonn, W.; Marques, D. d. M.; Resumos do XVII Simpósio Brasileiro de Recursos Hídricos, São Paulo, Brasil, 2007.

17. Santos, I. R.; Burnett, W. C.; Godoy, J. M.; Braz. J. Oceanogr. 2008, 56, 115.

18. Niencheski, L. F. H.; Windom, H. L.; Moore, W. S.; Jahnke, R. A.; Mar. Chem. 2007, 106, 546.

19. Godoy, J. M.; Carvalho, Z. L. d.; Fernandes, F. d. C.; Danelon, O. M.; Godoy, M. L. D. P.; Ferreira, A. C. M.; Roldão, L. A.; J. Braz. Chem. Soc. 2006, 17, 730 .

20. Burnett, W. C.; Peterson, R.; Moore, W. S.; de Oliveira, J. Estuar. Coast. Shelf $S$. 2008, 76, 501.

21. Oliveira, J.; Costa, P.; Braga, E. S.; J. Radioanal. Nucl. Chem. 2006, 269, 689.

22. Silva-Filho, E. V.; Sobral Barcellos, R. G.; Emblanch, C.; Blavoux, B.; Sella, S. M.; Daniel, M.; Simler, R.; Wasserman, J. C.; J. S. Am. Earth Sci. 2009, 27, 100.

23. Tomazelli, L. J.; Villwock, J. A.; Gravel 2005, 3, 6 .

24. Vieira, E. F.; Rangel, S. R. S.; Planície Costeira do Rio Grande do Sul, Ed. Sagra: Porto Alegre, 1988.

25. Villanueva, A. O. N.; Tese de Doutorado, Universidade Federal do Rio Grande do Sul, Brasil, 1997.

26. Fragoso Jr., C. R.; Dissertação de Mestrado, Universidade Federal do Rio Grande do Sul, Brasil, 2005.

27. Baumgarten, M. d. G. Z.; Rocha, J. M.; Niencheski, L. F. H.; Manual de análises em oceanografia química, Ed. da FURG: Rio Grande, 1996.

28. Strickland, J. L. H.; Parsons, T. R.; A practical handbook of seawater analysis, Bull. Fish. Res. Board. Can.: Otawa, 1972.

29. Arar, E.; Collins, G. B. Em Method 445.0; U.S., N. E. R. L., Ed. Environmental Protection Agency: Cincinnati, 1997.

30. Hammer, Ø.; Harper, D. A. T.; Ryan, P. D.; Palaeontologia Electronica 2001, 4,9 .
31. Santos, I.; Machado, M.; Niencheski, L.; Burnett, W.; Milani, I.; Andrade, C.; Peterson, R.; Chanton, J.; Baisch, P.; Aquat. Geochem. 2008, 14, 133 .

32. Scivittaro, W. B.; Silva, C. A. S. d.; Muraoka, T.; Trivelin, P. C. O.; Transformações do nitrogênio (15N) da uréia na cultura do arroz irrigado, Embrapa Clima Temperado: Pelotas, 2005.

33. Fragoso, C. R.; Collischonn, W.; Marques, D. d. M.; Resumo do X Congresso Brasileiro de Limnologia, Ilhéus, Brasil, 2005.

34. Baumgarten, M. d. G. Z.; Niencheski, L. F. H.; Trop. Oceangr. 2010, 38 , 88.

35. Zarzur, S.; Tese de Doutorado, Universidade Federal do Rio Grande, Brasil, 2007.

36. Machado, S. L. d. O.; Marchezan, E.; Righes, A. A.; Carlesso, R.; Villa, S. C. C.; Camargo, E. R.; Ciência Rural 2006, 36, 65.

37. Oliveira, J.; Burnett, W. C.; Mazzilli, B. P.; Braga, E. S.; Farias, L. A.; Christoff, J.; Furtado, V. V.; J. Environ. Radioact. 2003, 69, 37.

38. Horn, D. P.; Geomorphology 2002, 48, 121.

39. Odum, E.; Fundamentals of Ecology, WB Saunders Co.: Philadelphia, 1959.

40. Gamier, J.; Blanc, P.; Benest, D.; J. Am. Water Resour. As. 1989, 25, 751.

41. Hecky, R. E.; Kilhan, P.; Limnol. Oceanogr. 1988, 33, 796.

42. Crossetti, L. O.; Cardoso, L. D. S.; Callegaro, V. L. M.; Alves-daSilva, S. M.; Werner, V. R.; Rosa, Z. M.; Motta Marques, D. D.; Acta Limnologica Brasiliensia 2007, 19, 315.

43. Abreu, P. C.; Odebrecht, C.; González, A.; J. Plankton Res. 1994, 16 , 737.

44. Araújo, M. A. R.; Pinto-Coelho, R. M.; Rev. Bras. Biol. 1998, 58, 405.

45. Henry, R.; Nunes, M. A.; Mitsuka, P. M.; Lima, N. D.; Casanova, S. M. C.; Rev. Bras. Biol. 1998, 58, 571.

46. Knoppers, B. Em Elsevier Oceanography Series; Björn, K., ed.; Elsevier, 1994, vol. 60, doi: 10.1016/S0422-9894(08)70014-X.

47. Redfield, A. C.; Ketchum, B. H.; Richards, F. A. Em The Sea; Hill, M. N., ed.; Interscience Pub.: New York, 1963, vol. 2. 


\section{FLUXOS DE NUTRIENTES ASSOCIADOS ÀS DESCARGAS DE ÁGUA SUBTERRÂNEA PARA A LAGOA} MANGUEIRA (RIO GRANDE DO SUL, BRASIL)

Carlos F. F. Andrade*, Luis F. H. Niencheski, Karina K. Attisano, Marcio R. Milani

Instituto de Oceanografia, Universidade Federal do Rio Grande, Campus Carreiros, km 8, s/n, 96201-900 Rio Grande - RS, Brasil Isaac R. Santos

Department of Oceanography, Florida State University, Tallahassee, FL 32306, United States of America

Idel C. Milani

Departamento de Engenharia Hídrica, Centro de Desenvolvimento Tecnológico, Universidade Federal de Pelotas, Campus Porto, Rua Gomes Carneiro, 1, 96019-610 Pelotas - RS, Brasil

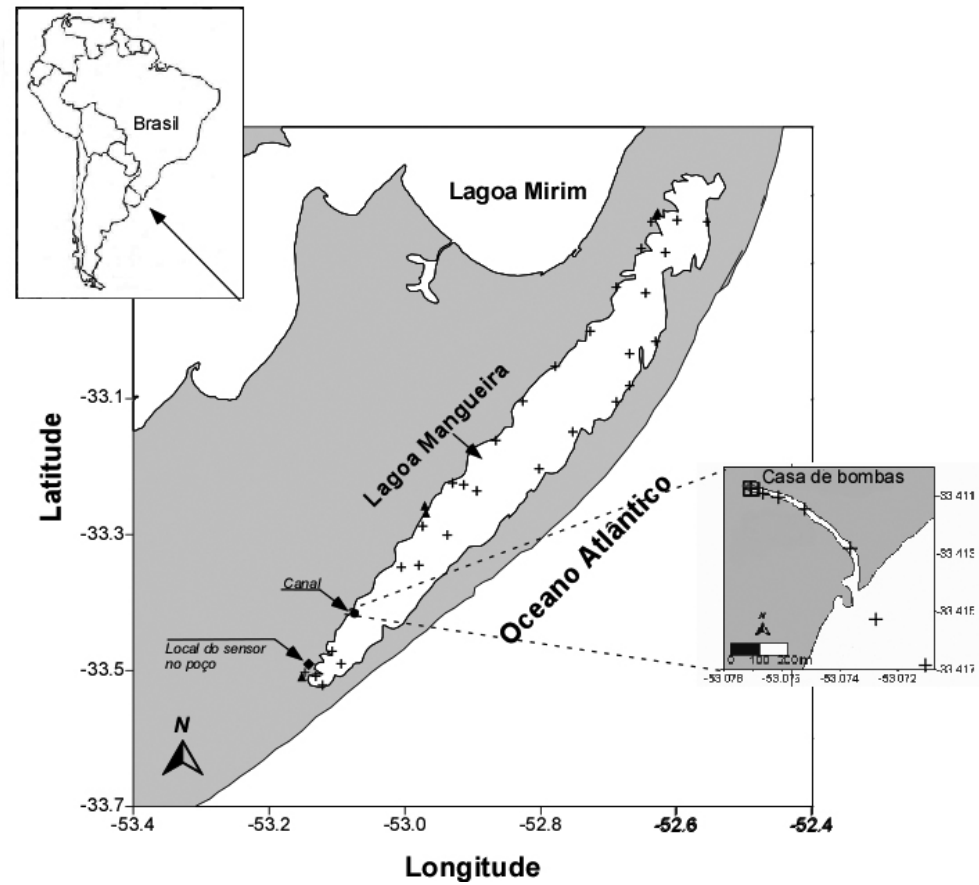

Figura 1S. Localização das estações amostrais: água do poço permanente (•); água superficial da Lagoa Mangueira incluindo o perfil amostral do canal (+); água dos poços piezométricos ( $\mathbf{\Delta})$ 